\title{
RELAÇÕES HÍDRICAS E TROCAS GASOSAS EM VINHEDO SOB COBERTURA PLÁSTICA ${ }^{1}$
}

\author{
GERALDOCHAVARRIA ${ }^{2}$, HENRIQUE PESSOA DOS SANTOS ${ }^{3}$, JOÃO FELIPPETO $^{4}$, \\ GILMAR ARDUÍNO BETTIO MARODIN ${ }^{5}$, HOMERO BERGAMASCHI $^{6}$, \\ LOANA SILVEIRACARDOSO ${ }^{7}$, FLÁVIO BELLOFIALHO ${ }^{8}$
}

RESUMO - No presente estudo, determinaram-se as influências da cobertura plástica impermeável (CP) sobre a demanda evaporativa atmosférica e o potencial da água no solo, bem como as consequiências destas sobre as trocas gasosas foliares (fotossíntese, condutância estomática e transpiração) e o potencial da água na folha da videira. As avaliações foram realizadas nos ciclos 2005/06 e 2006/07, em um vinhedo da cv. Moscato Giallo, conduzido em “Y”, com cobertura plástica impermeável tipo ráfia ( $160 \mu \mathrm{m})$, em 12 fileiras com $35 \mathrm{~m}$, deixando-se cinco fileiras sem cobertura (controle). Em ambas as áreas, avaliou-se o microclima quanto à temperatura do ar, umidade relativa do ar, radiação fotossinteticamente ativa e velocidade do vento, próximos ao dossel vegetativo. A CP aumentou a disponibilidade hídrica no solo nas entrelinhas e restringiu-a nas linhas, sobretudo em profundidades mais superficiais $(0-10 \mathrm{~cm})$. A CP também diminuiu a demanda evaporativa atmosférica, principalmente pela redução da velocidade do vento (-90\%), aumentando o potencial da água na folha e a condutância estomática. De modo geral, a CP pode favorecer a condição hídrica e elevar a capacidade de assimilação de carbono em videiras.

Termos para indexação: Condutância estomática, transpiração, demanda evaporativa, cultivo protegido, videira.

\section{WATER RELATIONS AND LEAF GAS EXCHANGE IN VINEYARD WITH PLASTIC OVERHEAD COVER}

\begin{abstract}
This study evaluated the plastic overhead cover (POC) effect on evaporative demand of atmosphere and soil water content, as well as their consequences on gas exchange (photosynthesis, stomatal conductance and transpiration) and leaf water potential in grapevine. The experiment was carried out during the 2005/06 and 2006/07 seasons, in a vineyard of 'Moscato Giallo', trained in "Y" and covered with an impermeable plastic cloth $(2.65 \mathrm{~m} \mathrm{x} 160 \mu \mathrm{m})$, in 12 rows with $35 \mathrm{~m}$, with five rows left uncovered (control). In both areas, the microclimate was evaluated, in terms of air temperature, air relative humidity, radiation photosynthetically active and wind speed above the canopy. The POC increased the soil water content between rows and restricted it in the most superficial depths of rows $(0-10 \mathrm{~cm})$. The POC also decreased the evaporative demand of atmosphere, mainly by reducing wind speed $(-90 \%)$, which increased the leaf water potential and stomatal conductance. In this way, POC can favor water conditions and increase leaf carbon assimilation in grapevines.
\end{abstract}

Index terms: Stomatal conductance, transpiration, evaporative demand, plastic overhead cover, vine.

\section{INTRODUÇÃO}

A condição hídrica da videira é um importante fator para a definição da qualidade enológica (Choné, 2001), sendo que moderados déficits hídricos estão associados a altos conteúdos de tanino e antocianina em uvas tintas (Mattheus et al., 1990; Van Leeuwen et al., 1994). Dessa forma, regiões que apresentam menores precipitações ou déficits hídricos controlados têm a possibilidade de aumentar a concentração de compostos desejáveis, diminuindo o teor de água nas bagas. Na Serra Gaúcha, ocorre uma tendência histórica ao excesso de chuvas no período de maturação, o que pode prejudicar a qualidade da uva em função da ocorrência de podridões ou pela necessidade de colheitas antecipadas (Tonietto \& Falcade, 2003). Para amenizar estes efeitos indesejáveis das chuvas, principalmente no aspecto fitossanitário, alguns viticultores estão empregando a cobertura plástica sobre as fileiras de cultivo. Essa técnica vem sendo utilizada principalmente na produção de uvas destinadas ao consumo in natura, há um longo período no Brasil, sendo

'(Trabalho 198-07). Recebido em: 13-08-2007. Aceito para publicação em: 29-10-2008

${ }^{2}$ Eng. Agr ${ }^{\circ}$ Dr. Pós-doutorando Universidade Federal do Rio Grande do Sul, Departamento de Horticultura e Silvicultura, CEP 91540-000, Porto AlegreRS. e-mail: geraldochavarria@ hotmail.com, Bolsista do CNPq.

${ }^{3}$ Eng. Agr ${ }^{\circ}$ Dr. Pesquisador Embrapa Uva e Vinho, CEP 95700-000, Bento Gonçalves-RS., e-mail: henrique @ cnpuv.embrapa.br

${ }^{4}$ Enólogo Mestrando Universidade Federal do Rio Grande do Sul, Departamento de Agrometeorologia e Forrageiras, CEP 91540-000, Porto Alegre-RS e-mail: joaofelipeto@gmail.com

${ }^{5}$ Eng. Agr ${ }^{\circ}$ Professor Dr. Departamento de Horticultura, Universidade Federal do Rio Grande do Sul, CEP 91540-000, Porto Alegre-RS. e-mail: marodin@ufrgs.br

${ }^{6}$ Eng. Agr ${ }^{\circ}$ Professor Dr. Departamento de Agrometeorologia, Universidade Federal do Rio Grande do Sul, CEP 91540-000, Porto Alegre-RS. e-mail: homerobe@ufrgs.br

${ }^{7}$ Eng. Agr ${ }^{\circ}$ Mestranda Universidade Federal do Rio Grande do Sul, Departamento de Agrometeorologia e Forrageiras, CEP 91540-000, Porto Alegre-RS e-mail: loanacar@yahoo.com.br

${ }^{8}$ Eng. Agr ${ }^{\circ}$ Dr. Pesquisador Embrapa Uva e Vinho, CEP 95700-000, Bento Gonçalves-RS., e-mail: bello@ cnpuv.embrapa.br 
associada ao uso de irrigação na maioria das situações (Santos, 2005). Entretanto, sua utilização na produção de uvas para vinificação é bastante recente e incipiente, principalmente pela falta de informações técnicas sobre este tipo de cultivo.

Alguns resultados, relacionados ao incremento de qualidade e produção vitícola pelo uso de $\mathrm{CP}$, já são conhecidos (Santos, 2005). Contudo, a interferência da cobertura sobre a condição hídrica das videiras, até o presente momento, não tem sido bem elucidada e carece de estudos, visando a definir um manejo adequado da planta e da irrigação neste sistema de cultivo. A cobertura plástica pode alterar o microclima da videira, em particular as temperaturas máximas, a disponibilidade de radiação solar e a presença de água livre sobre as folhas (Cardoso et al., 2007; Chavarria et al., 2007). Todavia, os reflexos dessa alteração do microclima sobre a fisiologia da planta e, sobretudo, em suas relações hídricas não são devidamente conhecidos.

Paradoxalmente à hipótese de que a cobertura plástica tenha a capacidade de restringir a água e incrementar a qualidade enológica, existe a possibilidade de essa tecnologia ser também uma ferramenta para o uso racional da água. Atualmente na agricultura, a disponibilidade de água tem gerado bastante discussão sobre a necessidade e o emprego de técnicas agrícolas que reduzam a utilização ou aumentem a eficiência do uso da água (Christofidis, 2002). A cobertura, por diminuir a radiação solar incidente na cultura, poderia atuar neste sentido, reduzindo a taxa evaporativa e, conseqüentemente, a demanda hídrica pela cultura (Barradas et al., 2005).

O objetivo do presente trabalho foi caracterizar as relações hídricas em vinhedo sob cobertura plástica, considerando, em conjunto, a disponibilidade e a distribuição de água no solo, a demanda evaporativa do microclima sob cobertura e as respostas foliares em termos de potencial da água e trocas gasosas.

\section{MATERIAL E MÉTODOS}

O experimento foi conduzido nos ciclos de 2005/2006 e 2006/2007, em vinhedos de uma vinícola localizada em Flores da Cunha-RS, distrito de Mato Perso ( $29^{\circ} 06^{\prime} \mathrm{S}, 51^{\circ} 20^{\prime} \mathrm{O}$ e altitude de $541 \mathrm{~m}$ ), utilizando-se a cultivar de uva branca Vitis vinifera $\mathrm{L}$. Moscato Giallo (clone VCR1), sobre porta-enxerto Kobber 5BB e com espaçamento de 3,0 x 0,9 m (3.703 plantas.ha $\left.{ }^{-1}\right)$.

As plantas foram conduzidas em " $\mathrm{Y}$ " com fileiras de 35 metros, na direção nordeste-sudoeste, com poda mista, deixandose varas de 6-8 gemas e esporões de duas gemas. O vinhedo foi dividido em duas partes, sendo uma das partes com 12 fileiras cobertas na linha de cultivo com lonas plásticas trançadas, transparentes, impermeabilizadas com polietileno de baixa densidade, com $160 \mu \mathrm{m}$ de espessura e largura de 2,65 m. Na outra parte, foram mantidas cinco fileiras descobertas, cujas linhas centrais foram consideradas como plantas-controle.

O microclima foi avaliado por medições de temperatura e umidade relativa do ar (psicrômetros de pares termoelétricos), velocidade do vento (anemômetro de conchas) e radiação fotossinteticamente ativa $(400-700 \mathrm{~nm}$, barras de 1,20 m equipadas com cinco células fotovoltáicas ligadas em série) nas áreas com e sem cobertura plástica, na altura do dossel vegetativo. Todos os sensores da área experimental foram conectados a sistemas de aquisição de dados (CR10 e CR21X, Campbell $\left.{ }^{\circledR}\right)$. Ambos os sistemas foram programados para efetuar leituras a cada minuto e médias a cada 30 minutos. Em frente ao vinhedo avaliado, foi instalada uma estação meteorológica automática Campbell ${ }^{\circledR}$, onde foram obtidos dados de pluviometria.

O déficit de pressão de vapor (DPV) foi calculado a partir dos dados de temperatura medida com psicrômetros de bulbo seco e úmido, sendo a diferença entre a pressão de saturação do vapor d'água e a pressão real de vapor, calculados pela equação de Tetens e pelo Método Analítico, respectivamente (Vianello \& Alves, 2000). Além disso, no segundo ciclo, também se determinou a taxa evaporativa da atmosfera (TEA, $\mu \mathrm{g} \cdot \mathrm{cm}^{-2} \cdot \mathrm{s}^{-1}$ ). Essa foi determinada com o uso de discos de papel-filtro (Marca: Whatman; Modelo: 41; 63,58 $\mathrm{cm}^{2}$ ) previamente pesados (massa seca do disco, MSD), submersos em água destilada por um período de um minuto (massa saturada do disco, MSatD), postos pendurados em posição próxima ao dossel vegetativo por cinco minutos e pesados novamente (massa úmida do disco, MUD). Sendo assim, obteve-se a taxa evaporativa através do cálculo:TEA $=[$ MSD $-($ MUD - massa seca do disco $)] /$ (área do disco*tempo). Foram realizadas quatro medições ao longo do dia $(9,11,14$ e 16 h), nas áreas coberta e descoberta e no mesmo momento, utilizando-se de três repetições (discos) em cada área.

No ciclo de 2006/07, ao longo de nove semanas a partir do início da maturação das bagas (mudança da cor em janeiro), foram realizadas coletas semanais de amostras de solo (aproximadamente $400 \mathrm{~g}$ ) dos vinhedos coberto e descoberto em três profundidades $(10 ; 20$ e $30 \mathrm{~cm})$. O solo coletado foi acondicionado em latas e vedado. As latas com solo foram pesadas e, após ficarem $72 \mathrm{~h}$ em estufa à temperatura de $60^{\circ} \mathrm{C}$, foram pesadas novamente. A partir das diferenças entre a massa úmida (MU) e a seca (MS), foi determinada a umidade no solo em base gravimétrica, sendo calculada a relação entre os dois tratamentos (coberto - ${ }_{\mathrm{Cob}}$ e descoberto - ${ }_{\text {Desc }}$ ) por: $(\%)=$ $\left[\left(\mathrm{MS}_{\mathrm{Cob}} * 100\right) / \mathrm{MU}_{\mathrm{Cob}}-\left(\mathrm{MS}_{\text {Desc }} * 100\right) / \mathrm{MU}_{\text {Desc }}\right]$.

Em cada área, coberta e descoberta, foram marcadas 10 plantas, nas quais foram realizadas medições de fotossíntese $\left(\mu \mathrm{mol} \mathrm{CO} \mathrm{CO}_{2} \cdot \mathrm{m}^{-2} \cdot \mathrm{s}^{-1}\right)$, condutância estomática $\left(\mathrm{mol} \mathrm{H}_{2} \mathrm{O} \cdot \mathrm{m}^{-2} \cdot \mathrm{s}^{-1}\right)$, transpiração $\left(\mathrm{mol} \mathrm{H}_{2} \mathrm{O} \cdot \mathrm{m}^{-2} \cdot \mathrm{s}^{-1}\right)$, temperatura foliar $\left({ }^{\circ} \mathrm{C}\right)$, e calculada a eficiência do uso da água [EUA $=$ fotossíntese $\left(\mu \mathrm{molCO} \cdot \mathrm{m}^{-2} \cdot \mathrm{s}^{-1}\right)$ / transpiração $\left(\mathrm{mol} \mathrm{H}_{2} \mathrm{O} \cdot \mathrm{m}^{-2} \cdot \mathrm{s}^{-1}\right)$, no período de mudança de cor das bagas de cada ciclo (11-01-06 e 19-01-07) e 30 dias após a colheita da safra de 2007 (28-03-07). As avaliações realizadas nos dias 11-01-06 e 19-01-07 foram efetuadas com o intuito de testar o contraste coberto-descoberto no mesmo estádio fenológico e em diferentes níveis de radiação solar e temperatura, enquanto a avaliação de 28-03-07 foi realizada para testar o mesmo contraste em estádios fenológicos distintos no mesmo ciclo. Para essas avaliações, utilizou-se um analisador de gases por radiação infravermelha (LI-6400, LI-COR, Lincoln, USA) equipado com câmara de topo aberto. Essas avaliações foram realizadas durante o dia, a cada duas horas, utilizando fluxo de ar de $500 \mu \mathrm{mol} . \mathrm{s}^{-1}$.

Nos mesmos dias e horários, também foi determinado o potencial da água na folha (MPa), o qual foi medido em 10 folhas coletadas aleatoriamente em cada área, com a utilização de uma 
câmara de pressão (Scholander et al., 1965). Para as medidas do potencial de base da água na folha, as folhas foram coletadas antes do amanhecer (4h30), nos dias: 02-11-05, 11-01-06, 13-0206, 06-03-06, 19-01-07 e 28-03-07. Para essas medidas, foram também utilizadas 10 folhas de cada área de cultivo.

$\mathrm{Na}$ análise estatística, utilizou-se o programa R (R, 2007), sendo que os dados de microclima (temperaturas média, mínima e máxima; umidade relativa; radiação solar e velocidade do vento) foram pareados, e as diferenças entre ambos os tratamentos foram analisadas por regressão linear. A significância do coeficiente angular das equações resultantes foi avaliada pelo teste t. Na análise dos dados de radiação solar e velocidade do vento, o intercepto foi fixado em zero, pois, quando a medida externa for nula, a interna deve também ser obrigatoriamente nula. As variáveis de disponibilidade relativa de água no solo, taxa evaporativa da atmosfera, trocas gasosas foliares (fotossíntese, condutância estomática e transpiração), temperatura foliar, eficiência do uso da água e potencial da água na folha foram submetidas à análise da variância, e as médias, comparadas pelo teste de Tukey, a 5\% de probabilidade.

\section{RESULTADOS E DISCUSSÃO}

A cobertura plástica proporcionou restrição na disponibilidade de água no solo na linha de cultivo, com diminuições de 20 a $60 \%$ ao longo do perfil de $30 \mathrm{~cm}$ de profundidade, em relação à área-controle (Figura 1A). Essa redução da umidade do solo foi mais drástica na profundidade de $0-10 \mathrm{~cm}$, atingindo mais de $60 \%$, comparada ao cultivo convencional (Figura 1A). Resultados semelhantes foram também encontrados por Santos (2005), que observou reduções de até $50 \%$ na disponibilidade hídrica do solo em áreas sob cobertura plástica, em relação às áreas sem cobertura, afetando principalmente a porção superficial $(0-10 \mathrm{~cm})$. Em função dessa limitação hídrica, houve nítida restrição do crescimento e sobreviviência da cobertura vegetal rasteira sob as fileiras das áreas protegidas.

Na entrelinha, em contrapartida, foi observada maior disponibilidade hídrica no cultivo protegido, em relação ao convencional, visto que a estrutura da cobertura concentra a água das chuvas apenas no espaço da entrelinha (Figura 1B).

No vinhedo sob cobertura plástica, também se observou diferenciação microclimática em relação à área sem cobertura (Tabela 1). Com relação à temperatura, as máximas diárias foram as que mais sofreram influência. À medida que a temperatura máxima diminui fora da cobertura, a redução correspondente sob a cobertura é menor. Isso pode ser verificado pela variação altamente significativa do coeficiente angular de regressão $\left(0,897 ; \mathrm{P}_{\beta=1}=0,0005\right)$, que indica que, para cada ${ }^{\circ} \mathrm{C}$ de redução na temperatura externa, a temperatura abaixo da cobertura cai $0,90^{\circ} \mathrm{C}$. Em função desse efeito, a temperatura média teve um efeito similar, porém, bem menor no coeficiente angular de regressão $(0,96$; $\left.\mathrm{P}_{\beta=1}=0,0265\right)$, indicando queda de $0,96^{\circ} \mathrm{C}$ sob a cobertura para cada ${ }^{\circ} \mathrm{C}$ de variação na temperatura externa. Esse efeito foi ainda menor nas temperaturas mínimas diárias $\left(0,972 ; \mathrm{P}_{\beta=1}=0,0012\right)$
(Tabela 1). Segovia et al. (1997) consideraram a menor movimentação de ar como o principal fator dessa maior amplitude térmica no ambiente protegido. Isto fica evidenciado nos resultados obtidos, pois a velocidade do vento foi atenuada em 90,04\% junto ao dossel vegetativo das plantas cultivadas sob cobertura plástica (Tabela 1). Apesar dessas alterações de temperatura e velocidade do vento, observou-se que a umidade relativa foi o parâmetro que teve menor variação em relação ao ambiente externo, sendo que para cada unidade percentual (u.p.) de variação externa, houve 0,85 u.p. sob a cobertura.

A radiação fotossinteticamente ativa sob a cobertura sofreu redução de $37 \%\left(0,629 ; \mathrm{P}_{\beta=1}<0,0001\right)$. O efeito variou de um ciclo para outro, tendo redução de $32,59 \%$ no primeiro ciclo e de 43,39\% no segundo ciclo, o que está relacionado à perda de transparência do plástico ao longo do tempo (Tabela 1). Rana et al. (2004) também observaram diminuição da radiação fotossinteticamente ativa, sendo atenuada em $17 \%$ em clarite e $32 \%$ em áreas cobertas com plástico impermeável e translúcido.

A velocidade do vento e a radiação solar incidente apresentam grande influência na renovação do ar na camada limítrofe da folha, o que, por sua vez, afeta o déficit de pressão de vapor (DPV) entre a folha e o ar. O efeito do DPV na abertura estomática tem sido estudado (Schulze, 1993), contudo pouco se sabe sobre a influência no crescimento das plantas (Cunningham, 2006). De maneira geral, os trabalhos sugerem que a diminuição do DPV aumenta o crescimento das plantas, por mudanças fisiológicas, como redução na transpiração e aumento da abertura estomática, incrementando a fotossíntese e a eficiência do uso da água (Schulze, 1993; Barradas et al., 2005; Cunningham, 2006).

De acordo com os resultados de microclima, a demanda evaporativa da atmosfera do vinhedo sob a cobertura plástica foi reduzida. Considerando o DPV nos dias em que foram realizadas as análises fotossintéticas, podemos claramente observar que as coberturas reduziram o DPV em 57,1\% quando comparados a vinhedos descobertos (Tabela 2). Em 11-01-06, o DPV de ambas as áreas foi maior, e a diferença entre ambas foi menor (média de -18,65\% na área coberta). Entretanto, em 19-0107 e 28-03-07, obtiveram-se os menores valores absolutos de DPV e as maiores diferenças relativas entre as áreas cobertas e descobertas. Essa diferença em demanda evaporativa com as coberturas também foi demonstrada com a avaliação direta da evaporação, medida em discos de papel-filtro no segundo ciclo, o qual teve redução de até $9 \%$ às $14 \mathrm{~h}$ na área coberta em relação à área descoberta (Figura 2). Isto se deve à redução de radiação solar e velocidade do vento que a cobertura exerce (Tabela 1), o que aumenta a pressão de vapor do ar e, conseqüentemente, diminui o déficit de pressão de vapor entre a atmosfera e a superfície evaporativa. Resultados semelhantes também foram observados por Barradas et al. (2005), com Prunus armenica L. cobertos com tela em condições áridas, onde foi constatado decréscimo na transpiração e, conseqüentemente, atenuação do estresse hídrico.

Nas duas avaliações realizadas ao longo do dia, o potencial da água na folha, de ambas as áreas, alcançou os menores valores entre 9 e $16 \mathrm{~h}$ (Figura 3 ). Os valores encontrados 
antes do amanhecer (potencial de base) variaram de - 0,12 a $-0,1$ MPa na área coberta e de -0,28 a -0,01 MPa na área descoberta, apresentando um desvio-padrão de 0,032 e 0,006 MPa, para os cultivos coberto e descoberto, respectivamente (Figura 3D). Essa menor variabilidade (desvio) das plantas cobertas no potencial de base, que é considerado o ponto de equilíbrio entre o solo e a planta (Van Zyl, 1987), demonstra maior estabilidade hídrica dessas plantas cultivadas sob cobertura plástica. Os potenciais de ambas as áreas encontraram-se adequados para o desenvolvimento e crescimento da videira (Ojeda et al., 2004); contudo, para o incremento da qualidade enológica, o potencial de base de água na folha deveria situar-se na faixa de - 0,2 a - 0,6 MPa, neste período de maturação (Ojeda et al., 2004).

O balanço hídrico da videira tem influência direta sobre a composição da baga, principalmente no teor de açúcar, na acidez (ácido málico e tartárico) e nos compostos fenólicos (taninos, antocianinas, flavonóides, etc.) (Carbonneau et al., 1978; Choné, 2001; Ojeda et al., 2004). Neste sentido, esperava-se inicialmente que a cobertura plástica pudesse promover um estresse hídrico moderado sobre as videiras e, com isto, pudesse atuar nestes processos de incremento de qualidade. Nas profundidades de 0$30 \mathrm{~cm}$, nas linhas, foi observada essa restrição hídrica. Entretanto, as alterações no microclima do vinhedo sob cobertura e, possivelmente, na distribuição do sistema radicial, favorecendo maior proporção nas entrelinhas, reduziram esse efeito restritivo de água sob a cobertura.

$\mathrm{Na}$ avaliação de trocas gasosas, pôde-se observar que a maior disponibilidade de radiação e maior DPV ocorridos em janeiro de 2006 foram determinantes dos maiores contrastes entre as áreas coberta e descoberta (Figura 4). Enquanto a condutância estomática e a fotossíntese foram significantemente superiores nas folhas das plantas cobertas nesta data (Figura 4A e 4D), na mesma época no ciclo de 2006/07, não se observaram diferenças em fotossíntese. No segundo ciclo, em janeiro, a principal diferença é a condição de dia nublado, o que reduziu drasticamente a radiação solar e o DPV no ambiente coberto, em relação ao descoberto. Nesse mesmo ciclo, em março, quando houve condições de maior DPV que em janeiro (Tabela 2), puderam-se observar diferenças na fotossíntese. Entretanto, pelo fato de as folhas de ambos os estádios apresentarem valores similares de condutância estomática, a diferença em fotossíntese observada em março pode ser mais relacionada ao atraso da senescência foliar, em teor de clorofila, nas áreas cobertas (Chavarria, 2008).

Com relação à transpiração, observa-se que a maior diferença entre as áreas coberta e descoberta ocorreu em janeiro de 2006 (Figura 4G, 4H e 4I), quando também se observaram as maiores diferenças em fotossíntese e abertura estomática. Neste sentido, destaca-se que as condições microclimáticas impostas pela cobertura, pelo fato de favorecerem a abertura estomática, podem contribuir diretamente para o aumento da transpiração. Entretanto, os dados de microclima (menor velocidade do vento e DPV na área coberta) e os valores similares de potencial da água na folha não sugerem a ocorrência de maior transpiração nas plantas cobertas. De fato, a transpiração foi semelhante entre os tratamentos nas avaliações de janeiro de 2007 (Fig. 4H).
O fato de a cobertura plástica propiciar maior abertura estomática, em condições semelhantes de disponibilidade hídrica do solo, demonstra que a relação entre assimilação de $\mathrm{CO}_{2} \mathrm{e}$ consumo de água foi alterada pela cobertura plástica. Nesta condição, a eficiência do uso da água, considerando a produtividade (EUAp), poderia ser mais apropriada do que a EUA com base nas trocas gasosas para evidenciar um possível efeito da cobertura plástica (Larcher, 2000). Entretanto, para se obter essa informação, são necessários os valores de evapotranspiração e crescimento total em massa seca, o que não pôde ser realizado neste experimento por ser um vinhedo comercial. Com o conhecimento da EUAp será possível determinar as exigências hídricas sob as coberturas plásticas e, conseqüentemente, adequar os estresses hídricos moderados que são benéficos na qualidade enológica.

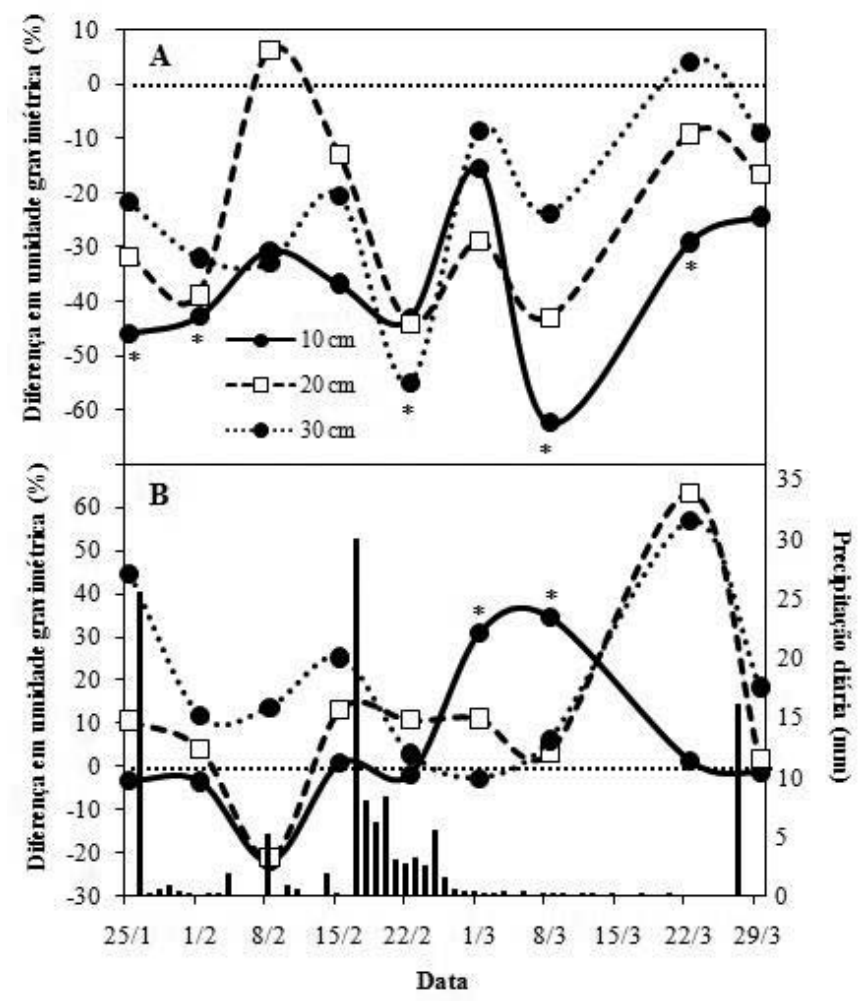

FIGURA 1- Diferença da umidade gravimétrica do solo na linha (A) e na entrelinha (B) em três profundidades (10; 20 e $30 \mathrm{~cm}$ ), em vinhedo com cobertura plástica, em relação a vinhedo sem cobertura plástica, no período da mudança de cor à colheita, no ciclo de 2006/07. Flores da Cunha-RS. 2007. Cada símbolo representa o valor médio de três repetições. * representa $\mathrm{P}<0,05$, de acordo com o teste de Tukey, entre os tratamentos com e sem cobertura plástica. 


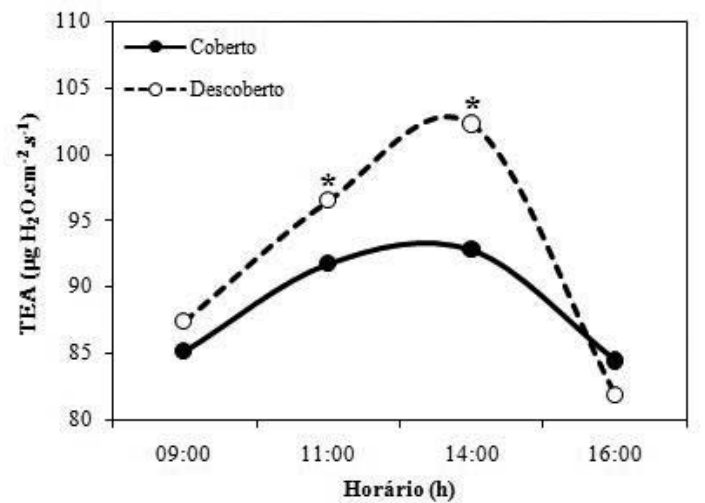

FIGURA 2- Taxa evaporativa da atmosfera sob cobertura plástica e em cultivo convencional, utilizando-se de discos de papel. Flores da Cunha-RS, 2007. Cada símbolo representa o valor médio de três repetições. * representa $\mathrm{P}<0,05$, de acordo com o teste de Tukey, entre os tratamentos com e sem cobertura plástica.
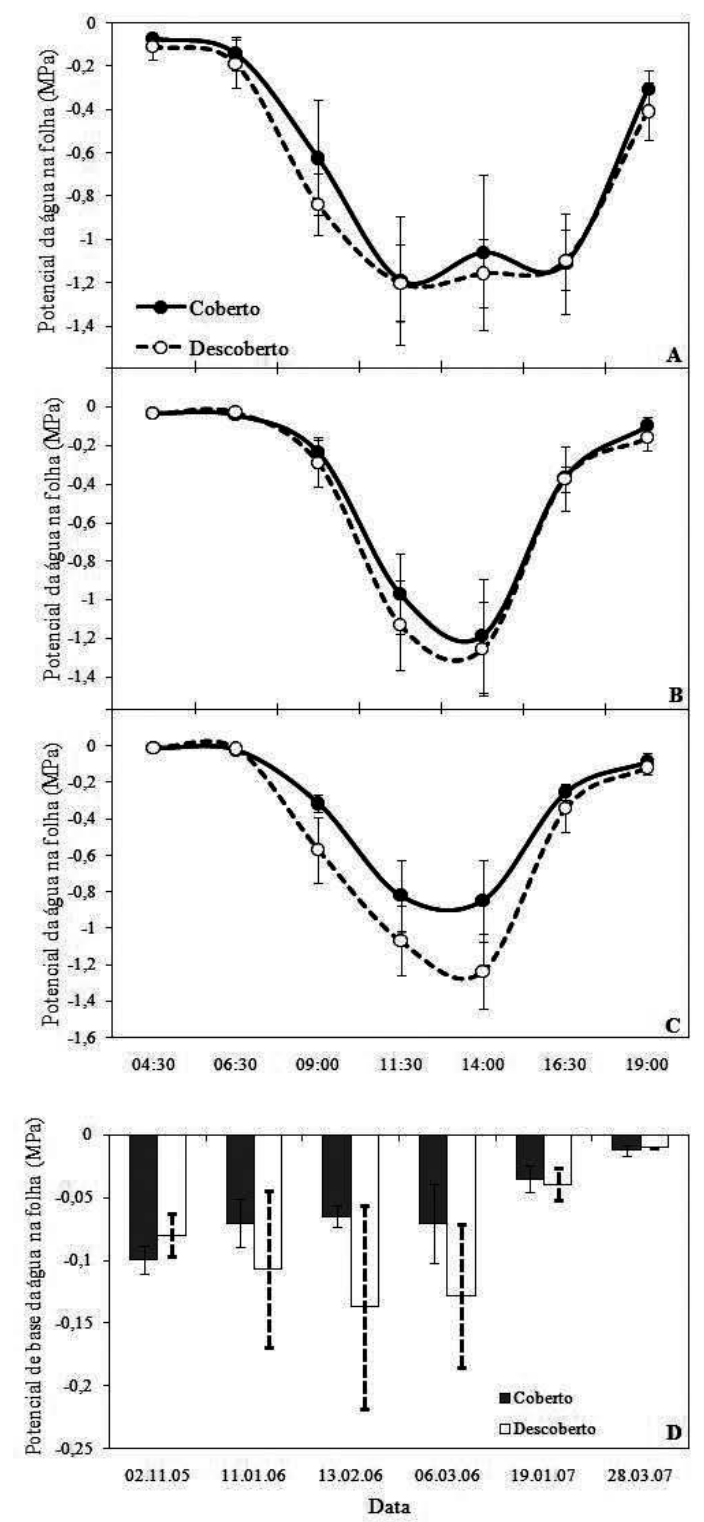

FIGURA 3- Potencial de água na folha ao longo do dia (A - 11-01-06, B - 19-01-07 e C - 28-03-07) e potencial de base (D) medido antes do amanhecer, realizado em videiras cultivadas sob cobertura plástica e em cultivo convencional. Flores da Cunha-RS, 2007. Cada símbolo representa o valor médio de 10 repetições \pm desvio-padrão.* representa $\mathrm{P}<0,05$, de acordo com teste de Tukey, entre os tratamentos com e sem cobertura plástica. 


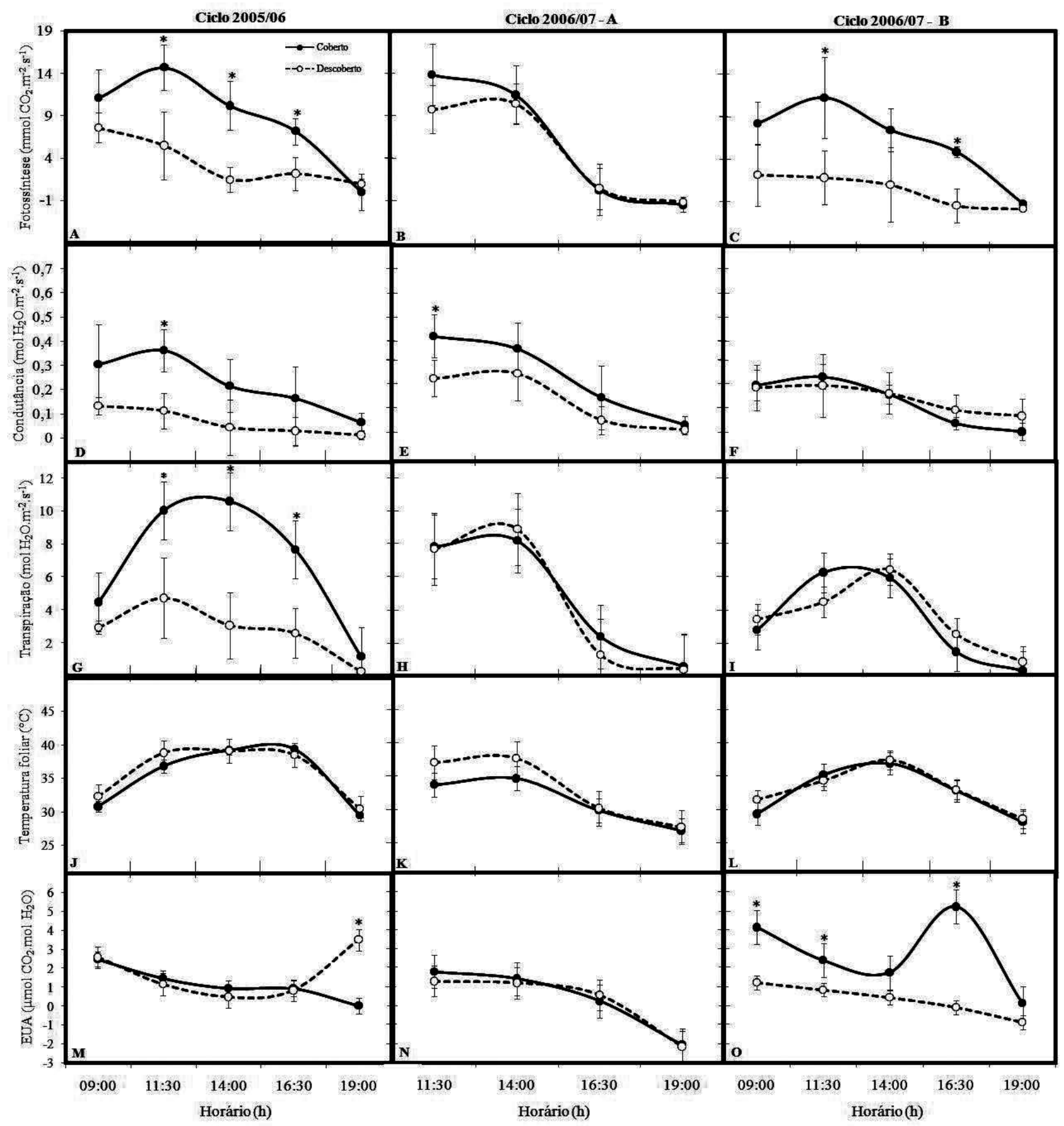

FIGURA 4- Fotossíntese (A-C), condutância estomática (D-F), transpiração (G-I), temperatura foliar (J-L) e eficiência do uso da água (M-O) em folhas de videiras 'Moscato Giallo' cultivada sob cobertura plástica (coberto) e em cultivo convencional (descoberto). Estas avaliações foram realizadas no dia 11-01-06 (A, D, G, J e M) do ciclo de 2005/06 e nos dias 19-0107 (B, E, H, K e N) e 28-03-07(C, F, I, L e O), na safra de 2006/07, em Flores da Cunha-RS. Cada símbolo representa o valor médio de 10 repetições \pm desvio- padrão. * representa $\mathrm{P}<0,05$, de acordo com teste de Tukey, entre os tratamentos com e sem cobertura plástica. 
TABELA 1-Médias diárias das observações microclimáticas em vinhedo da cultivar Moscato Giallo conduzida em "Y” com cobertura plástica (C) e descoberto (D), no ciclo de 2005/06 e 2006/07. Flores da Cunha-RS, 2006 e 2007.

\begin{tabular}{|c|c|c|c|c|c|c|}
\hline \multirow{2}{*}{$\begin{array}{l}\text { Variáveis microclimáticas } \\
\text { (médias diárias dos ciclos) }\end{array}$} & \multicolumn{2}{|c|}{$2005 / 2006$} & \multicolumn{2}{|c|}{$2006 / 2007$} & \multirow{2}{*}{\multicolumn{2}{|c|}{ Equações de regressão $* * *$}} \\
\hline & Coberta & Descoberta & Coberta & Descoberta & & \\
\hline Tmáx. dossel $\left({ }^{\circ} \mathrm{C}\right)$ & 31,94 & 28,19 & 30,37 & 31,8 & $\begin{array}{l}C=4,51+0,897 \mathrm{D} \\
\mathrm{R}^{2}=0,74\end{array}$ & $(\mathrm{P}=0,0005)^{*}$ \\
\hline Tmédia dossel $\left({ }^{\circ} \mathrm{C}\right)$ & 21,28 & 20,28 & 21,91 & 21,84 & $\begin{array}{l}\mathrm{C}=1,37+0,960 \mathrm{D} \\
\mathrm{R}^{2}=0,95\end{array}$ & $(\mathrm{P}=0,0265)$ \\
\hline Tmín. dossel $\left({ }^{\circ} \mathrm{C}\right)$ & 14,7 & 14,5 & 16,33 & 16,07 & $\begin{array}{l}\mathrm{C}=0,64+0,972 \mathrm{D} \\
\mathrm{R}^{2}=0,94\end{array}$ & $(\mathrm{P}=0,0012)$ \\
\hline Umidade relativa dossel (\%) & 83,2 & 82,51 & $*$ & $*$ & $\begin{array}{l}\mathrm{C}=13,2+0,848 \mathrm{D} \\
\mathrm{R}^{2}=0,89\end{array}$ & $(\mathrm{P}<0,0001)$ \\
\hline Radiação solar dossel (MJ.m $\left.{ }^{-2} \cdot \operatorname{dia}^{-1}\right)$ & 5,38 & 7,98 & 4,32 & 7,63 & $\begin{array}{l}\mathrm{C}=0,629 \mathrm{D} \\
\mathrm{R}^{2}=0,91\end{array}$ & $(\mathrm{P}<0,0001)$ \\
\hline Velocidade do vento diária $\left(\mathrm{m} \cdot \mathrm{s}^{-1}\right)$ & 0,09 & 0,904 & 0,08 & 0,82 & $\begin{array}{l}\mathrm{C}=0,107 \mathrm{D} \\
\mathrm{R}^{2}=0,49\end{array}$ & $(\mathrm{P}<0,0001)$ \\
\hline
\end{tabular}

*ausência de dados devido a problemas nos sensores (termopares de bulbo úmido).

**probabilidade de o coeficiente angular ser igual a 1 (não haver diferença entre coberto e descoberto), pelo teste t.

***Equações de regressão referentes à análise das variáveis microclimáticas dos dois anos agrícolas em conjunto, pois não houve interação significativa entre ano agrícola e efeito da cobertura, sendo este último similar nos dois anos.

TABELA 2 - Radiação fotossinteticamente ativa e déficit de pressão de vapor ao longo do dia, em vinhedo da cultivar Moscato Giallo conduzida em "Y" com cobertura plástica e descoberto (testemunha), nos dias 11-01-2006, 19-01-2007 e 28-03-2007. Flores da Cunha-RS, 2006 e 2007.

\begin{tabular}{|c|c|c|c|c|c|c|}
\hline \multicolumn{7}{|c|}{ Radiação fotossinteticamente ativa $\left(\mathrm{W} \cdot \mathrm{m}^{-2}\right)$} \\
\hline \multirow[b]{2}{*}{ Hora } & \multicolumn{2}{|c|}{ 11-01-06 } & \multicolumn{2}{|c|}{ 19-01-07 } & \multicolumn{2}{|c|}{ 28-03-07 } \\
\hline & Coberto & Descoberto & Coberto & Descoberto & Coberto & Descoberto \\
\hline 8 & 164 & 326 & 154 & 519 & 124 & 406 \\
\hline 10 & 419 & 730 & 915 & 303 & 494 & 178 \\
\hline 12 & 619 & 942 & 149 & 481 & 158 & 399 \\
\hline 14 & 557 & 763 & 184 & 460 & 216 & 407 \\
\hline 16 & 375 & 529 & 396 & 1332 & 816 & 193 \\
\hline \multirow[t]{2}{*}{18} & 330 & 450 & 74 & 254 & 24 & 70 \\
\hline & \multicolumn{2}{|c|}{$\mathrm{C}=0,660 \mathrm{D} *$} & \multicolumn{2}{|c|}{$\mathrm{C}=0,362 \mathrm{D}$} & \multicolumn{2}{|c|}{$\mathrm{C}=0,437 \mathrm{D}$} \\
\hline \multicolumn{7}{|c|}{ Déficit de pressão de vapor $(\mathrm{kPa})$} \\
\hline & \multicolumn{2}{|c|}{$11-01-06$} & \multicolumn{2}{|c|}{ 19-01-07 } & \multicolumn{2}{|c|}{ 28-03-07 } \\
\hline Hora & Coberto & Descoberto & Coberto & Descoberto & Coberto & Descoberto \\
\hline 8 & 0,31 & 0,48 & 0,04 & 0,21 & 0,02 & 0,01 \\
\hline 10 & 1,00 & 1,26 & 0,05 & 0,66 & 0,28 & 0,64 \\
\hline 12 & 1,87 & 2,18 & 0,30 & 0,86 & 0,33 & 1,16 \\
\hline 14 & 2,79 & 3,12 & 0,01 & 1,10 & 0,42 & 1,25 \\
\hline 16 & 2,89 & 3,36 & 0,01 & 0,12 & 0,37 & 1,21 \\
\hline \multirow[t]{2}{*}{18} & 1,56 & 1,88 & 0,02 & 0,09 & 0,04 & 0,30 \\
\hline & \multicolumn{2}{|c|}{$\mathrm{C}=0,868 \mathrm{D}^{*}$} & \multicolumn{2}{|c|}{$\mathrm{C}=0,131 \mathrm{D}$} & \multicolumn{2}{|c|}{$\mathrm{C}=0,334 \mathrm{D}$} \\
\hline
\end{tabular}

*análise de regressão linear, considerando radiação (RFA) e déficit de pressão de vapor (DPV) na área coberta (C) em relação à área descoberta (D) $(\mathrm{P}<0,0001)$.

\section{CONCLUSÕES}

1-Sob a cobertura plástica ocorreu restrição hídrica no solo, nas linhas de cultivo da videira, e aumentou a disponibilidade hídrica nas entrelinhas. Esse efeito foi mais evidente nas camadas superficiais do solo $(0-10 \mathrm{~cm})$.

2-A cobertura plástica não afetou o potencial da água na folha, mas diminuiu a demanda evaporativa diária. Desse modo, esta tecnologia apresenta-se como um atenuante para estresses hídricos, favorecendo a condutância estomática e, conseqüentemente, a assimilação de carbono em videiras.

\section{REFERÊNCIAS}

BARRADAS, V.L.; NICOLÁS, E.; TORRECILLAS, A.; ALARCÓN, J.J. Transpiration and canopy conductance in Young apricot (Prunus armenica L.) trees subjected to different PAR levels and water stress. Agricultural Water Management, Amsterdam, v.77, p.323-333, 2005.

CARBONNEAU, A.; CASTERAN, P.; LECLAIR, P.H. Essai de détermination, en biologie de la plante entière, de relations essentielles entre le bioclimat naturel, la physiologie de la vigne et la composition du raisin. Méthodologie et premiers résultats 
sur les systèmes de conduite. Annales D'élioration de Plantes, Paris, v.28, n.2, p.195-221. 1978.

CARDOSO, L. S.; BERGAMASCHI, H.; COMIRAM, F.; CHAVARRIA, G.; MARODIN, G. A. B.; DALMAGO, G. A.; SANTOS, H. P.; MANDELLI, F. Alterações micrometeorológicas em vinhedos pelo uso de coberturas de plástico. Pesquisa Agropecuária Brasileira, v.43, p.441-447, 2008.

CHAVARRIA, G. Ecofisiologia e fitotecnia do cultivo protegido de videiras cv. Moscato Giallo (Vitis vinifera L.). 2008. 136p. Tese (Doutorado em Fitotecnia) - Faculdade de Agronomia, Universidade Federal do Rio Grande do Sul, Porto Alegre, 2008.

CHAVARRIA, G.; SANTOS, H.P.; SÔNEGO, O.R.; MARODIN, G.A.B.; BERGAMASCHI, H.; CARDOSO, L.S. Incidência de doenças e necessidade de controle em cultivo protegido de videira. Revista Brasileira de Fruticultura, Jaboticabal, v.29, n.3, p.477-482, 2007.

CHONÉ,X.; LEEUWEN, C.V.; DUBORDIEU,D.; GAUDILLÈRES, J.P. Stem water potential is sensitive indicator of grapevine water status. Annals of Botany, London, v.87, p.477-483, 2001.

CHRISTOFIDIS, D. Irrigação, a fronteira hídrica na produção de alimentos. Irrigação e Tecnologia Moderna, Brasília, n.54, p.46$55,2002$.

CUNNINGHAM, S.C. Effects of vapour pressure deficit on growth of temperate and tropical evergreen rainforest of Australia. Acta Oecologica, Paris, v.30, p.399-406, 2006.

LARCHER, W. Ecofisiologia vegetal. São Carlos: Rima Artes e Textos, 2000. 531p.

MATTHEWS, M.A.; ISHII, R.; ANDERSON, M.M.; O'MAHONY, $M$. Dependence of wine sensory attributes on vine water status. Journal of the Science of Food and Agriculture, Chichester, v.51, p.321-335, 1990 .

OJEDA, H.; DELOIRE, A.; WANG, Z.; CARBONNEAU, A. Determinación y control del estado hídrico de la vid. Efectos morfológicos y fisiológicos de la restriction hídrica en vides. Viticultura Enologia Profesional, Castelldefels, v.90, p.27-43, 2004.
R. Development Core Team. R: A language and environment for statistical computing. R. Foundation for statistical computing. Vienna, Austria, Disponível em: 〈http://www.r-project.org/ >. Acesso em: 01 dec. 2007.

RANA, G.; KATERJI, N.; INTRONA, M.; HAMMAMI, A. Microclimate and plant water relationship of the "overhead" table grape vineyard managed with three covering techniques. Scientia Horticulturae, Amsterdam, v.102, p.105-120, 2004.

SANTOS, H. P. Fruteiras de clima temperado em cultivo protegido: desafios e perspectivas em videira e macieira. Bento Gonçalves: Embrapa Uva e Vinho, 2005. 44 p. (Documentos, 52).

SCHOLANDER, P.F.; HAMMEL, H.T.; BRADSTREET, E.D.; HEMMINGSEN, E.A. Sap pressure in vascular plants. Science, Washington, v.148, p.339-347, 1965.

SEGOVIA, F. O.; ANDRIOLO, J.L.; BURIOL, A. G.; SCHNEIDER, F. M. Comparação do crescimento e desenvolvimento da alface (Lactuca sativa L.) no interior e no exterior de uma estufa de polietileno em Santa Maria, RS. Ciência Rural, Santa Maria, v.27, n.1, p.37-41, 1997.

SCHULZE, E.D. Soil water deficits and atmospheric humidity as environmental signals. In: SMITH, J.A.C., GRIFFITS, H. (Ed.). Water deficits: plant responses from cell to community. Oxford: BIOS Scientific, 1993, p.129-145.

TONIETTO, J.; FACALDE, I. Regiões vitivinícolas brasileiras: uvas para processamento. Bento Gonçalves: Embrapa Uva e Vinho, 2003. 134p. (Frutas do Brasil, 34).

VAN LEEUWEN, C. ; SEGUIN, G. Incidences de l'alimentation en eau de la vigne, appréciée par l'état hydrique du feuillage, sur le développement de l'appareil végétatif et la maturation du raisin (Vitis vinifera Variété Cabernet Franc, Saint-Emilion 1990). Journal International des Sciences de la Vigne et du Vin, Bordeaux, v.28, p.81-110, 1994

VAN ZYL, J.L. Diurnal variation in grapevine water stress as a function of changing soil water status and meteorological conditions. South Africa Journal for Enology and Viticulture, South Africa, v.8, p.45-52, 1987.

VIANELLO, R.L.; ALVES, A.R. Meteorologia básica e aplicações. Viçosa: UFV, 2000.449p. 